Session 2793

\title{
The Positive Impacts of Design Projects in Freshman Courses
}

\author{
Dr. Saeed D. Foroudastan, Ms Linda O. Hardymon \\ Middle Tennessee State University \\ Engineering Technology \& Industrial Studies Department
}

\begin{abstract}
To enhance learning and encourage freshmen students to continue within the pre-engineering and engineering technology curriculums, Middle Tennessee State University modified its introductory engineering course to incorporate not only the fundamentals required to the support basic engineering course learning experience, but to include a design project. The hands-on design concept makes the course more interesting and more challenging, and gives the students a taste of real-world applications as motivation to continue with engineering or engineering technology as their major. Through a design project, students gain a better understanding of engineering or engineering technology as a career through exposure to the various disciplines the project requires. Several years ago, the professor of the introductory course initiated the concept of project involvement with one requiring simple drawings and models involving redesign of a door to solve an actual ventilation situation at the cogeneration plant. Realizing that small design assignments added value to the course, the question arose, why simulate a real-world project when the opportunity to do one is there? Since then, the students have progressed to the design and construction of a solar/battery-powered vehicle offering design and design problem issues, use of knowledge, physical application, comprehension of engineering principles, and teamwork that adhere to the learning objectives of the class. A bonus to the solar project is a national competition that can be entered to test the capabilities of the final project. Another design project choice is a moon buggy that upon completion can be entered in a NASA sponsored competition. The projects presented as assignments are short term (one semester) and positive experiences. The students are enthusiastic about these design projects that offer them an understanding of engineering and engineering technology and motivate them to take additional courses within the engineering curriculum. They gain a much better "sense" of engineering. Design projects in freshmen courses improve the course content, improve enrollment, and have a positive impact on the learning experience.
\end{abstract}

\section{Introduction}

While studying recruiting and retention issues for the Engineering Technology and Industrial Studies Department at Middle Tennessee State University (MTSU), one of the professors took an innovative approach in his introductory engineering fundamentals course by using a simple 
design project to test the use of knowledge being taught and to challenge the creativity of the students. The students enrolled in the class met the challenge with interest and enthusiasm. Since then, the course has been enhanced with progressively more difficult projects being offered.

Including a project is an opportunity to stimulate interest and enthusiasm in the students in the freshman courses. Many become bored in their introductory courses, not seeing the need to study and gain the knowledge of the fundamentals. Addition of a design project gives the students immediate feedback on the use of that fundamental knowledge. Even though the inclusion of the design project was introduced in the engineering fundamentals course, upper level students serving as team leaders provide some assistance with project and design development. This effort advances discovery and understanding of the fundamentals while promoting learning through hands-on applications for all students involved.

Introductory courses primarily taken by freshmen entering an engineering or engineering technology major include all the necessary basics of engineering. Putting the information into practical use via a design project stimulates interest and makes sense. At MTSU, the professor has taken the project application one step further by the addition of construction of the design produced. With a project-based learning experience having emphasis on teamwork, the freshmen and their team leaders have come to understand the educational preparation necessary for realworld competition in the workplace. The projects implemented at MTSU are unlike the usual projects offered. They offer a hands-on type of project application not usually offered to freshmen and, in addition, offer a unique opportunity to enter their final product in a national competition. The projects developed with the course create an element of excitement among the students.

Design and construction projects give the students a better understanding of real world expectations when selecting engineering or engineering technology as a career choice. As the freshmen are exposed to the various engineering disciplines involved in their choice of projects, value is added to the course and the students develop a desire to learn, are motivated to take additional courses within the department, and appreciate the taste of real world applications provided. Thorough training in the fundamentals of engineering education is enhanced through the hands-on applications when theory is partnered with design.

With a focus on using technologies to make the project assignment successful and competitive, the motivation and challenge of a project enhances the objective of teaching engineering with practical and relevant situations. Routinely, students face the challenge of adapting to issues relevant to working in engineering, learn by doing rather than through lecture/examination situations, and enrich their education through involvement in projects introducing a broad range of engineering technologies. The positive influence of project involvement improves the education of future engineers.

\section{First project introduced}

As the idea of a design project for freshmen was being considered, the opportunity for an initial assignment using a real-life problem became available. A solution was being discussed on campus requiring attention to a ventilation problem at the campus cogeneration plant. Presented 
to the class as a problem statement, the semester project was to offer reasonable solutions. The situation involved putting into use a low-cost means of cross ventilation in the turbine area of the plant allowing the overhead doors to be open, but keeping the accumulation of leaves and debris outside the area.

The assignment was merely to use simple drawings to resolve the problem. The students formed teams and worked together to offer several creative solutions using the knowledge from the course. The students took it one step further and built models to present their design solutions. Size, shape, materials, mechanical parts, and creativity of design varied for each team. As the students were required to integrate basic knowledge from the disciplines introduced in the course, they also learned to define the problem, assess on their own features of the problem, layout the management of a project, and develop and evaluate solutions. The success of the design project prompted the students to continue in engineering courses and set the stage for the use of more design projects in future semesters.

A survey completed by the students revealed a high degree of interest and appreciation for the applied, hands-on opportunities. The professor was encouraged with the results and decided to take the design project idea to a higher level. With the realization that small design assignments added value to the course, the question arose, why simulate a real-world project when the opportunity to do one is there? Since then, the students have progressed to a more challenging project entailing design and design problem issues, use of knowledge, physical application, comprehension of engineering principles, and teamwork that adhere to the learning objectives of the class.

\section{More innovative projects}

When a small solar vehicle offering a higher level of mechanical and electrical challenges became available for the class to use as a project, the design element of the course developed further. The solar/battery powered, pedal less vehicle offered many additional opportunities to put to use the introductory engineering basics. Forming teams, the students met the design and construction challenges enthusiastically. As they got involved in the issues and problems associated with the design of the vehicle, their interest grew. Questions relating to the frame such as type, size, and materials had to be addressed. In addition, this project offered something new and different from usual projects. The end result of design and construction could be entered in

\section{$\underline{\text { Solar Vehicle Project }}$}
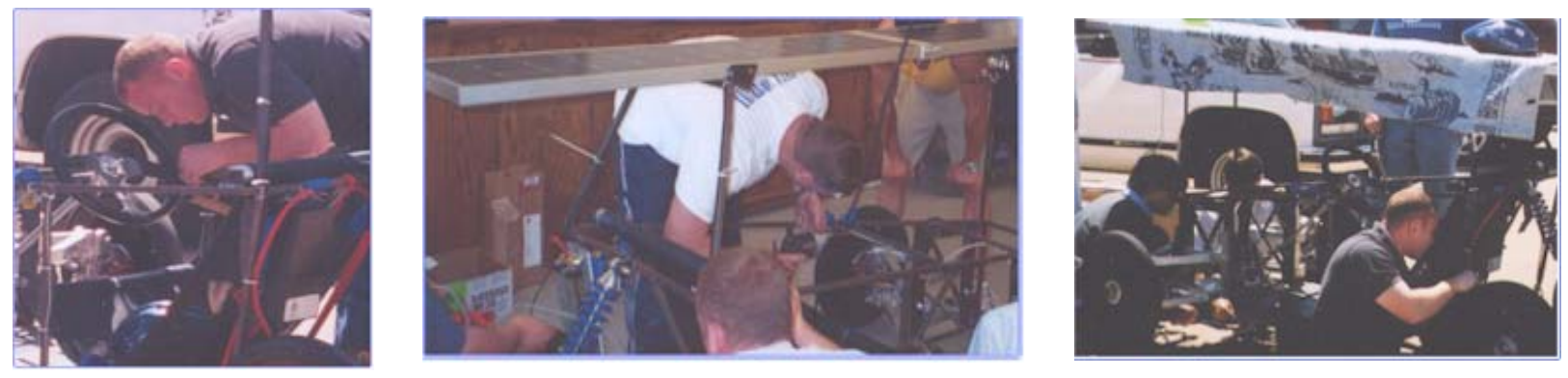

Proceedings of the 2003 American Society for Engineering Education Annual Conference \& Exposition Copyright (C) 2003, American Society for Engineering Education 
organized competition at a national race with support from the university and industry. Placement of components on the vehicle frame, following regulations regarding specifications, and many other design elements critical to being competitive in the race, added a new dimension to the project.

Some groups of students worked with the motor, motor controller, brakes, steering and other components associated with mechanicals. Another group worked with batteries, solar panels, wiring, and electrical considerations. Others students worked on issues of optimizing the subsystems of the vehicle, minimizing weight and achieving maximum efficiency. The students applied fundamentals from the course, researched their ideas, and developed the capability to design, analyze, develop models, and construct their project. They learned to work independently and work effectively as teams. They learned the value of working together, gaining a sense of responsibility to each other through the hands-on project.

The bonus to the project was the opportunity to participate in a national race to prove the capabilities of all decisions made regarding their design and construction choices. Thus another element to the project was introduced - the operation of a race-worthy vehicle using solar technology. To participate, the students had to meet stringent regulations, pass mechanical, electrical, and safety inspections of their vehicle, and develop a racing strategy. Upon entering the race and under actual race conditions, several problems occurred. The battery was discharging too quickly, the motor was overheating, the motor control malfunctioned, there appeared to be an issue with the gear ratio, but the students did not quit. Each predicament was addressed as it occurred, and each time they reentered the track. Overall, a project that began as a simple design problem and developed into an entry into a national race, was a huge success. It offered problem solving, communication, ethics, and gave the students a better 'sense' of engineering as a career.

\section{Further project application}

Another project introduced in the freshmen course involves design and construction of a 'moonbuggy' for use in an outer space application. As with the solar vehicle, there are established criteria and specifications for designing and building the machine. There is also a national competition sponsored by NASA to enter upon completion of the project. Again, teamwork is a critical part of producing a competitive buggy. The students learn the ins and outs of a project from discovery to completion.

\section{Moonbuggy design}
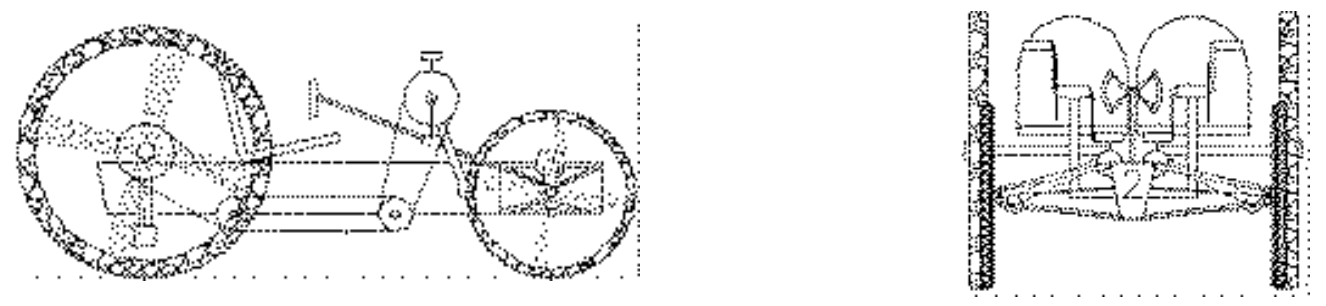
The contest actually begins with an unassembled vehicle of very specific specifications, followed by assembly and course testing in front of a panel of judges. The class-designed vehicle, yet to be constructed, will consist of a frame, drive train, suspension, steering, and brakes. The moonbuggy must be portable, collapsible, carry two passengers, and cover a terrain similar to the moon and strewn with lunar-like obstacles distributed randomly around the course.

For the class, the first stage of the moon buggy was a design and plan only contribution to the course. The next stage is actual construction and entry in the NASA sponsored national competition as representatives of the University. In addition to the design and construction planning (of a test model nature, rather than final production model), there are written and oral sections of the final competition requiring the team to explain and defend their choices. Many conversations over details about the advantages and disadvantages of components and decisions should prepare the students for these phases of the competition.

\section{Importance of design project selection}

Project selection is important. Each project must complement the fundamental engineering education that the course provides and suit the learning objectives of the class while providing an understanding of engineering disciplines. Decisions on design project selection for the freshmen must be result oriented and offer positive experiences in order to engage the students in the subject matter and encourage them to take additional engineering or engineering technology classes. Students must be motivated and challenged.

Projects should be short term, lasting one semester. With a vehicle already constructed, the project for the next semester may be limited to solving one of the problems associated with past experience. For the solar vehicle for example, solving the problem with the battery discharge rate or the overheating motor could be the design assignment for the class. Relocation of mechanical or electrical components on the frame for more efficient use of space or more efficient use of the solar technology could be considered for the next project. Choices are endless.

Some of the objectives of the incorporation of the design project into the lecture course content include:

- Show the use of engineering fundamentals in engineering

- Show the use of engineering fundamentals in design projects

- Show the role engineering analysis plays in design and problem solving

- Show the students how to use specific skills in design and problem solving processes

- Get freshmen students to work together and function as a team

- Help students decide which disciplines interest them

- Help students develop project problem solving skills and solutions

- Encourage freshmen to take additional courses

- Provide more contact between students and faculty

- Expose students to real-world design, construction, and problem solving situations

- Help students gain a better understanding of engineering or engineering technology as a career 


\section{Conclusion}

Design projects selected for the freshmen engineering students must fit the requirements of the course. At the end of the semester, the students should have the ability to appropriately apply the fundamentals. The addition of the project gives them the ability to also integrate the knowledge from the different engineering disciplines to define a problem, evaluate solutions, and be adaptable and capable to do so. With the national competition element, these projects offer far more excitement than usual projects.

Addition of a design project requires a change from the traditional course structure of lecture, book problems, and exams. A design project offers a great opportunity for more inquiry and discovery sessions. Restructure of the course and inclusion of an opportunity for hands-on, project-based learning at the freshmen level has created interest and enthusiasm for the MTSU students, along with some degree of self-motivation. It is obvious that working on the construction portion of the project entailed time in addition to the regular lecture time. Students leaving the course are better informed and gain a 'sense' of engineering. They have gained an ability to apply the fundamental knowledge. And for the future, the students are prepared to function as a team, understand responsibility, communicate, and make use of the techniques and skills they learned for engineering practice. Students are motivated to continue in their degree programs and enroll in further engineering courses.

The faculty members involved with the design projects are more visible to the students and aid in improving the course content. They help the students meet some of the key elements of the $21^{\text {st }}$ century job market by providing a quality program that is relevant to the student's needs. The department improves enrollment and gains some recognition when the students compete in the national events.

As the professor leads the students through the design process, many engineering disciplines are introduced, the stage is set for more design projects in future courses, students are enabled to better qualify for cooperative or internship positions, and engineering technology is promoted. Design projects offering an active and participatory engineering environment in freshmen courses improve the course content and have a positive impact on the learning experience.

DR. SAEED D. FOROUDASTAN

Saeed Foroudastan is an Associate Professor in the Engineering Technology and Industrial Studies Department at Middle Tennessee State University. With a B.S. in Civil Engineering (1980), an M.S. in Civil Engineering (1982), and a Ph.D. in Mechanical Engineering (1987) from Tennessee Technological University, his employment vitae includes: Instructor of Mechanical Engineering for Tennessee Technological University, Assistance Professor of Mechanical Engineering for Tennessee Technological University, Senior Engineer, Advanced Development Department, Textron Aerostructures, and Middle Tennessee State University. He is involved with several professional organizations and honor societies, and has many publications to his name. He also holds U.S. and European patents.

\section{LINDA O. HARDYMON}

Linda Hardymon is a Certified Energy Manager, coordinator for the Center for Energy Efficiency at Middle Tennessee State University, and adjunct faculty for the Engineering Technology and Industrial Studies Department. With a B.S. in Environmental Science and Technology and an M.S. in Industrial Studies, emphasis in safety, from Middle Tennessee State University, she organizes activities and conferences for professionals in the fields of energy and facilities management, has several publications, and is the administrative advisor for the Solar BikeRayce Team. 